\title{
Developing a model of effective growth for small and medium business for sparsely populated and remote areas within the framework of the green economy concept (based on the example of the Irkutsk region)
}

\author{
Andrei Mashovich ${ }^{1}$, Vytaliy Ruposov ${ }^{1, *}$, and Vladimir Moskvitin ${ }^{1}$ \\ ${ }^{1}$ Irkutsk National Research Technical University, 664074, Lermontova str., 83, Irkutsk, Russia
}

\begin{abstract}
The paper addresses the results of research in the field of creation of new "green" technologies and their economic validity. The authors argue that the trend of the remote territories' development should become the basis of the effectiveness of introduction of these technologies. Economic disproportions in the development of such territories have led to the creation of technologies that allow using local resources. As a result of the research, a model for the development of the depressed areas through the creation of effective growth points using the opportunities of small and medium entrepreneurship has been elaborated.
\end{abstract}

The point of growth arises on the market (or on the market segment) as an opportunity to meet the primary demand for a certain product or service. The very possibility to satisfy this demand appears locally and has a very specific territorial connection. In remote areas, the economy is a more or less holistic and internally related system, in which growth in one sector has the potential to significantly impact related sectors [1]. With low population density in the absence of competitive goods that are in demand on the global market, territories are forced to develop in the conditions close to subsistence economy. The development of small and medium business is spontaneous, with limited material and information resources that gives rise to fierce competition in tackling tactical tasks and does not virtually have prospects in the strategic aspect. Complex development of the territories of the Russian Federation is the urgent task. The results of this study justify the use of the point of growth models for small and medium business. The creation of a model that allows establishing interaction between economic entities and their increasing competitiveness will allow providing development of sparsely populated areas in the Irkutsk region and in other regions.

Existing growth models are developed mainly for territories with relatively high population density, logistic structure and raw materials base. The concept of growth points is based on the hypothesis of unbalanced or polarized economic development, based on the works of the French economist Francois Perroux, who noted that the formation of growth is

* Corresponding author: ruposov@istu.edu 
not instantaneous and does not happen everywhere. It occurs only at certain points or poles and then spreads out to the peripheral territories. At the same time, the distribution channels for that growth can be different, as well as the effects that it exerts on various elements of socio-economic systems [2,3].

In the global economy, the most financially strong companies dominate and take their own advantage turning into the growth points. Their impact on the subjects interacting with them transforms the surrounding space and leads to the formation of growth zones. In the growth zone, a transformation of economic relations and a change in the conditions of economic activity takes place. At the same time, the growth is spreading by involving the activities of neighboring growth points into the sphere of interest. The result is the appearance of relatively independent macro units [4], which have characteristic features, including:

- a basic industry that has a significant potential for growth and is capable of spreading the multiplier effect;

- a group of related industries capable for transferring the effect to the entire economy;

- a group of closely located productions that provide for an external effect.

In the formation and development of the growth points in the region, the process of spreading innovation is fundamental $[5,6,7,8]$. When a large urban system with a developed industry and a scientific base with the highest level of income per capita show innovative activity, a wave of innovations from this growth point spreads to the adjacent territories, and their well-being is increasing.

The territories located between the points of growth and providing infrastructural communication become additional sources of development, as the traffic flows increase and the innovation component spreads out. Consequently, they become the axes of development, forming together with the points of growth and peripheral territories the spatial framework of the regional economy (Figure 1).

On the territory of the Irkutsk region such an approach has just a limited applicability and is practically at the stage of degradation, rather than development. Large enterprises not only ceased producing their positive influence on peripheral or undeveloped territories, but also experience problems in their own development. The development of new territories generates environmental issues and depletion of resources, for example, in the timber industry.

The increase of the population density around the city-forming enterprises, which is clearly seen on the Figure 1, has practically reached the limits of its growth, and in some cases there is the opposite trend (de-urbanization). The underdeveloped logistical system adds its specifics into the development. With relative proximity to Irkutsk (Listvyanka in a straight line is $62 \mathrm{~km}$ far from Irkutsk, average travel time is $53 \mathrm{~min}$.; Bolshie Koty is $68 \mathrm{~km}$ far from Irkutsk, but in spring and autumn it can take the whole day to get there), the time for materials delivery can differ in several times.

Therefore, the ultimate goal of developing a model of the growth points is to create a network of interconnected small and medium-sized enterprises based on material resources and needs of a region that has territories remote from the developed infrastructure using the "green economy" concept. In the course of the study it has been established that in sparsely populated areas business is developing spontaneously, in the conditions of limited material and financial resources. The basic principle of its existence is subsistence economy, which negatively affects the quality and quantity of goods- and services-aimed sale. A large number of manual universal labors hinders the specialization and takes a lot of time from the main activity. One of the objectives of the growth points to be organized is to reduce the time and financial costs when performing non-core activities of small and medium-sized businesses. For this purpose, it is proposed to organize a central point of growth under the regional administration, the task of which will be the systematization of incoming questions, determining which specialized structure, when and under what conditions can solve these issues, and also informing the entities about this. At the first stage, it is enough to organize 
four points of growth in the areas of tourism, construction, food and waste processing. Activities in these areas are carried out in educational, scientific and production centers, and what is needed is just linking them to a systematic solution of practical problems.

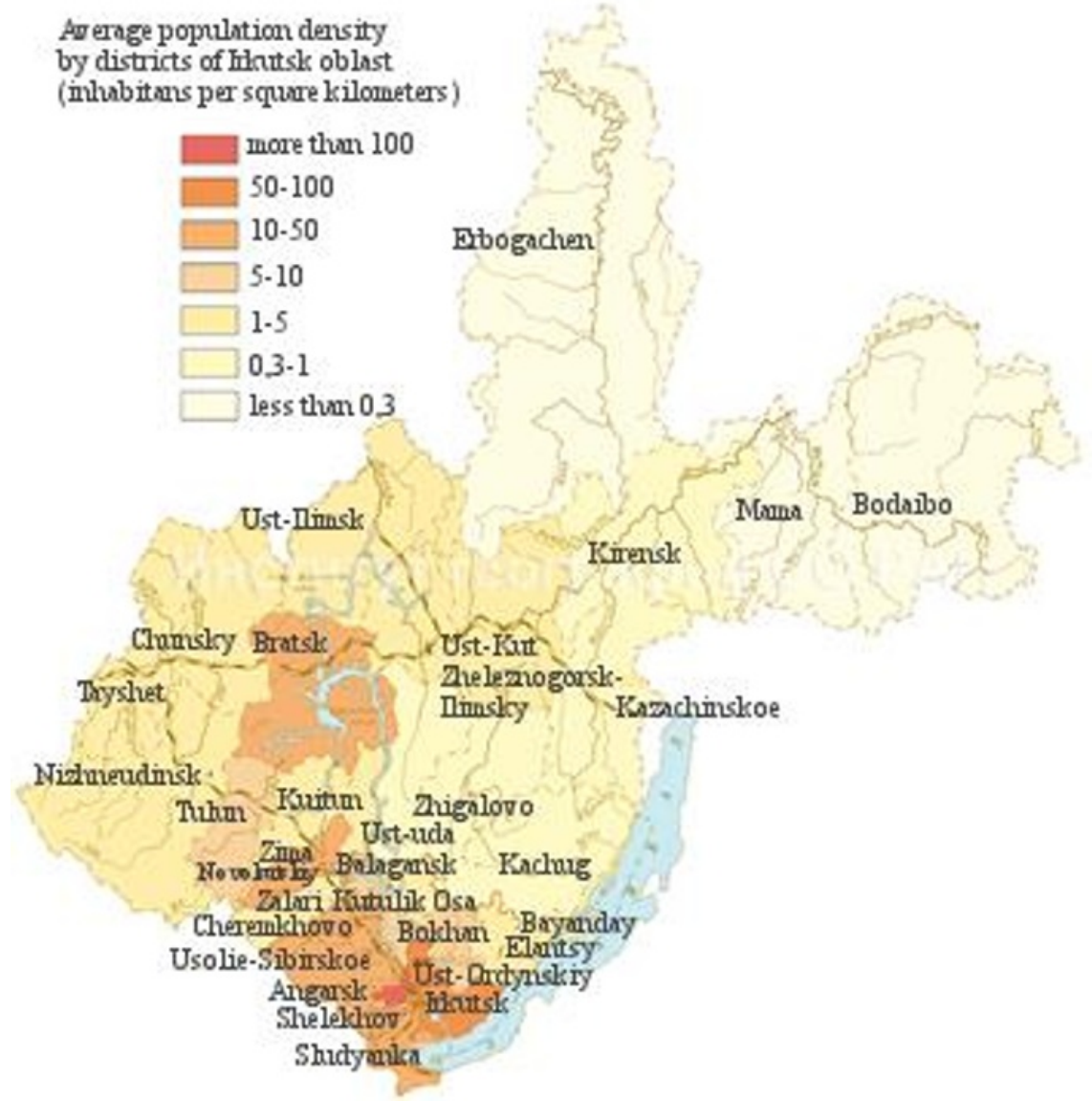

Fig. 1. Map of the average density of population of the Irkutsk region.

In connection with the territorial remoteness of business entities associated with the point of growth, the main type of interaction should be a distant one with the use of modern means of communication. Obviously, for most of the territories under consideration, the production of goods and services can be associated with the development of tourism that is conditioned by the geographical factors of the proximity of Lake Baikal. However, for successful implementation of this direction of development, it is necessary to create a growth driver that ensures interconnection with the centers of global tourism [9]. Attempts to lure tourists in large numbers to this or that remote tourist base for a long time are mostly doomed to failure. Short visits to tourist sites for familiarization with the peculiarities of this area look much more promising. Implementation of this approach is only possible, provided that the sites to be visited will differ, taking into consideration local specifics. Of course, we are not talking about the imposition of a particular business model, but preferential information, legal and commercial support to the specialized structures will allow solving local tactical tasks taking into account the strategic development of the region and the country. Tourists traveling from one place to another, should not only see the changing natural conditions, but also get acquainted with local attractions. One of the features can be environmentally clean local food, which differs from one neighboring camp site to another and meets modern standards of 
quality. In the forest area, game meet and wild plants can be used, in the steppe - the products of sheep breeding, in places with water resources - different types of fish. It is hard to imagine that the owner of a small tourist center or a hotel can solve such problems. This requires a network of small enterprises that are assisted not only in interaction with each other, but also help in selling surplus production to neighboring regions. When developing territories, a separate task is the processing and utilization of waste, which should also be solved with the help of specialized enterprises. Implementation of the assigned tasks will require buildings and facilities that meet modern security requirements, energy saving, comfort, etc. Today, for a number of reasons arising at the design, financing and construction stages, there is no possibility for such construction activity in the remote areas. Centralized development of the priority fields in this area, supported by economically sound projects based on mobile professional small enterprises, attracting local raw materials and human resources, will help stimulating the development of sparsely populated areas. The economic growth should be based on specialized structures providing information, legal and commercial support, which can be linked to a particular direction or be of a general nature [10]. It is the information support in choosing the premises, technologies, equipment and staffing that a small entrepreneur very much needs [11].

The obvious interrelation of the chosen directions: tourism, construction, food and waste recycling, does not exclude their internal contradictions based on the desire to get the maximum profit. The attractiveness of tourist routes is largely due to comfortable and safe accommodation, tasty and cheap food, nature friendly environment that require costs, which will pay off after a long period of time. At the same time, firms involved in the construction, production of food and waste management require payment (prepayment) immediately after the provision of services, and in conditions of lack of competition, such firms may dictate prices. Therefore, the economic regulation of these relationships is one of the tasks of the growth points. At the initial stage, the objects most promising for development, for example, a company operating in the field of tourism and wishing to expand are to be selected. Recommendations and proposals necessary for that company to meet modern requirements and the possibility of subsidizing are to be developed. Proposals can be either individual or standard. In the center of growth, segmentation of a number of firms based on the similarity of problems is to be made, and assistance in obtaining financial resources provided. As the tourism firms develop, they ensure the functioning of small businesses engaged in construction, food production and waste processing. Thus, a connection will be made between the directions and their development. An assessment of the quality of services, for example, timeliness and cost of garbage removal, is to be carried out by the administration of the tourist hostel and downloaded into the point of growth database, which will provide independent price-quality control at minimal cost. Thus, the financial flows should first of all be directed to the development of innovative tourist projects, from where they will get to the construction, food and environmental sectors. The availability of finance will allow timely paying for the buildings to be constructed, for the products to be supplied, for the waste to be exported and processed, that is, will make these directions cost-effective.

The construction sector, in contrast to big cities, where large firms are struggling for the orders that cost billions, in the sparsely populated and remote areas needs the information support. The information on innovative technologies, orders, local human and raw materials resources, standard low-rise construction projects available in databases will allow reducing expenses for materials and logistics costs, ensuring stable profits at a relatively low cost of the object. A similar situation is observed in the food and environmental sectors.

Small and medium business, developing in all four directions, will need modern and safe buildings and facilities, the availability of which in the Irkutsk region is no more than $5 \%$. To reduce the costs of such construction of high quality, it should be based on small professional mobile groups specializing in standard projects based on the energy efficient 
filler structures. Relying on the databases available at the growth points, it will be possible to make maximum use of local resources, implement the customer's wishes in the field of design or specific features of the future production.

Spontaneous organization of one's own business in the absence of scientifically grounded qualified assistance, based on the use of improvised means and limited financial possibilities does not allow expecting compliance with the concepts of the "green economy": the efficient use of natural resources, preservation and increase of natural capital, reduction of pollution, energy efficiency, etc.

Limited sales markets, information, human and material resources do not allow developing; more often they make surviving on the basis of an anti-ecological model of the "brown" economy ${ }^{\dagger *}$.

The existing recommendations elaborated in the developed countries with high population density and relatively mild climate cannot be effective in the conditions of the Irkutsk region and similar areas. For example, the Internet is clogged with information about rapid return of the energy-saving fluorescent mercury lamps. It does not take into account that in remote areas (for example, tourist bases) the tasks to organize collection, storage, removal and delivery of old lamps are practically unfeasible. The processing of such lamps in sparsely populated areas is not cost effective due to small volumes, and here is the slow spread of mercury, including the territories around Baikal. The promised energy efficiency also does not work [12]. Due to poor quality of electricity and climatic conditions, the lifetime of lamps is usually lower than promised, and the heat energy released by lighting is not saved, but used for heating of housing. This is just one example where generic recommendations that do not take into account the specifics of the region are not effective and can harm the environment. Therefore, the development of a scientifically based model for the organization and conduct of business, taking into account the specifics of the region, will displace the "brown" economy and facilitate the development of business.

Solving the issues of creating new profitable enterprises taking into account all these features are very urgent tasks for the conditions of the scarcely developed territories of the Irkutsk region and of other regions. To address these issues, a database of small innovative enterprises in the Irkutsk region has been created with the participation of higher education establishments, and the organizations capable of implementing projects in the remote areas have been selected [13].

The points of growth model, structurally presented in the Figure 2, reflects the main directions of the study of conditions for the formation of the business model, taking into account the projects, most prepared for implementation.

The implementation of the "green technology" concept is to be based on the use of innovative thermal insulation materials obtained on the territory of the Irkutsk region, in close proximity to the market. The purchase of raw materials for the development of prototypes, using materials circulating in the industry of the Irkutsk region is to be done with this purpose. There next stages are the creation of model samples of energy-efficient filler structures with the use of innovative technology for manufacturing composite polymeric heat-insulating materials with fillers from waste products; working out of a technology for the production and use of new materials on the model samples; the development of guidelines for small and medium business for the use of this technology on the example of Priolkhon territory.

*The "brown" economy is the current model of the economy. 


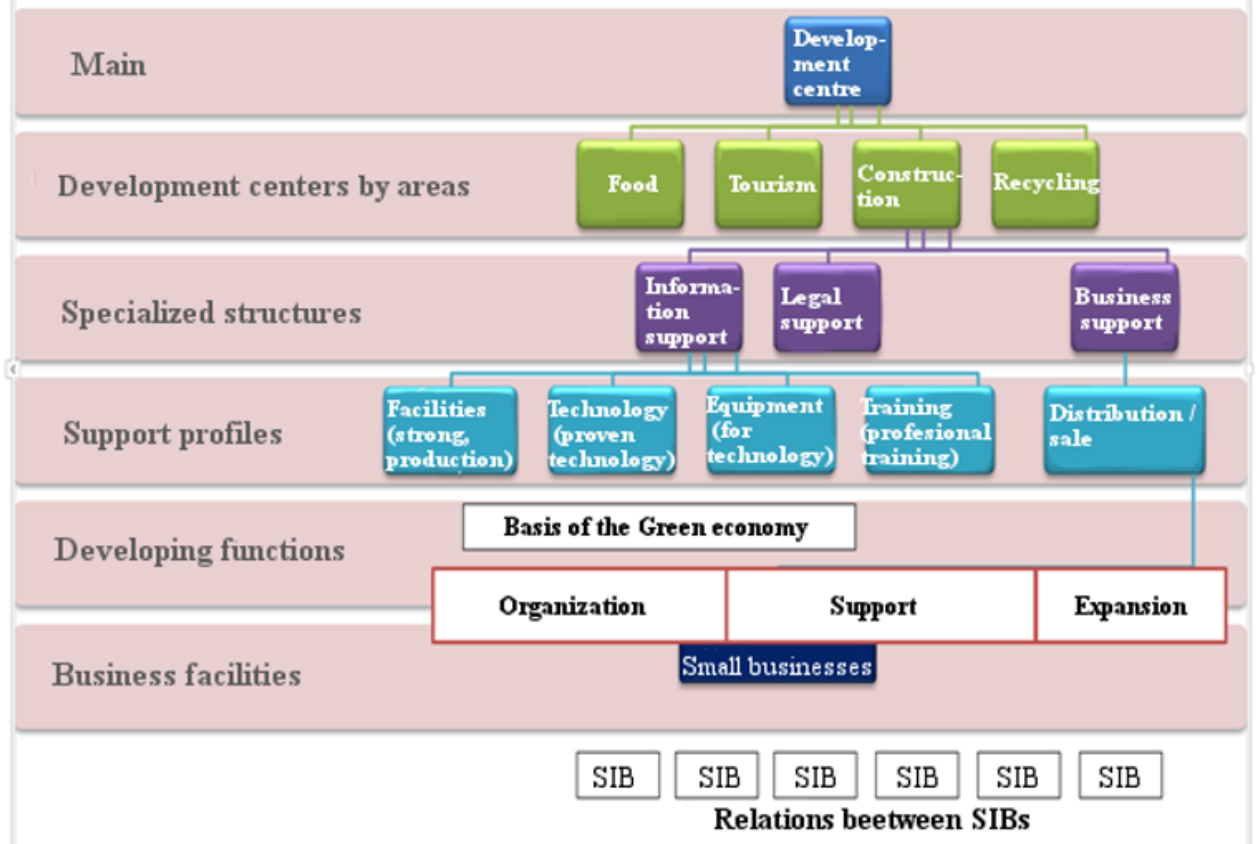

Fig. 2. The scheme of implementation of the points of growth.

To create efficient growth points, it is necessary to identify the main factors that will influence the successful creation of small and medium-sized enterprises. Economic and mathematical models are used for this. The economic-mathematical model allows describing mathematically the totality of characteristics of an economic object or process with the purpose of their research and management. Such models relate to the mathematical record of the economic problem being solved [14-16].

As a result of the use of mathematical methods, a more complete study of individual factors influence on general economic indicators of the organizations activities, and a reduction in timing of the analysis is achieved, the accuracy of economic calculations is improved, and multidimensional analytical problems that cannot be performed by traditional methods are solved. In the process of using economic and mathematical methods in economic analysis, the development and analysis of economic and mathematical models that describe the influence of individual factors on generalized economic performance of organizations are carried out.

For this work, two main types of models were chosen:

1. Multifactor econometric model;

2. Extrapolation model.

The first model allows creating a simulation model of the center's (of the growth point) activity taking into account all necessary factors and their interrelations, considering not only economic factors, such as economic parameters, demographic dynamics, solvency of the population, but social factors as well, related to the involvement of the population in entrepreneurial activities.

The second model based on the multifactorial econometric model of the simulation type allows developing forecasts how the key parameters of the economic environment will change when influencing on various factors of the external environment.

The relationship between the factors has been determined by such economicmathematical methods as correlation and regression analysis, analysis of statistical indicators, and econometric methods. 
The creation of the economic-mathematical model allowed determining what factors are most important for the creation of small enterprises for the realization of the necessary conditions for effective entrepreneurship. The model allows forming the parameters of a small enterprise in the following areas:

1. Technological component.

2. Number and qualification of staff.

3. Necessary amount of the initial capital.

4. Required equipment (both for purchase and for renting or ordering services and outsourcing work).

5. Tax environment, the possibility of using benefits and concessional financing.

6. The necessary level of new knowledge for the implementation of technology.

7. Formation of the management system.

The rationale for the development of small and medium business, through the creation of economic and mathematical modeling is constantly taking place, both in the Russian Federation and in other countries.

The elaborated model has made it possible to draw a conclusion about the need to create or select technologies that have high ecological efficiency, which can be developed in remote territories, in conditions of limited resources.

According to the model, a set of parameters has been defined for a typical construction enterprise, which can operate in the remote and sparsely populated areas.

1. The enterprise must possess the technology of prefabricated structures using local raw materials.

2. Personnel: 1 engineer, 2 technicians, and 4 workers.

3. Initial capital of 700000 rubles.

4. Equipment: a mobile installation for the creation of new materials, and a car.

5. Use of tax incentives associated with the creation of scientific and technical products.

6. New technologies for creating materials from local raw materials.

7. Creation of a project management system.

The analysis of the logistics component of the economic model allows approving the thesis on the efficiency of transportation of the key resources and equipment only. It is necessary to use the opportunities formed on a particular territory using the mechanism of development of growth points.

\section{References}

1. L. N. Ivanova, G. A. Terskaya, Journal of Institutional Research, 7(2), 120-131 (2015)

2. F. Perroux, Regional economics: theory and practice (The Free Press, New York, 1970)

3. S.V. Raevsky, Yu. I. Isachenko, Regional Economy: Theory and Practice, 3(378), 2-14 (2015)

4. History of economic thought (Peter, St. Petersburg, 2008)

5. E. P. Amosenok, V. A. Bazhenov, Region: Economics and Sociology, 2, 134-145 (2006)

6. N. N. Dumnaya, New market economy (MAKS-Press, Moscow, 2009)

7. L. G. Iogman, Development of the scientific and technical potential of the region (Komi Scientific Center of the Ural Branch of the Russian Academy of Sciences, Syktyvkar, 2009)

8. C. B. Kortov, Innovations, 6, 25-33 (2004)

9. M. V. Kuklina, T. A. Bayaskalanova, Mediterranean Journal of Social Sciences, 6(S7), (2015) 
10. T. A. Bayaskalanova, D. D. Chimitova, A. S. Gamanets, N. V. Dneprovskaya, O. G. Ulturgasheva, G. A. Bayaskalanova, N. V. Shobdoeva, Yu. A. Saltykova, A. V. Chernavina, E. A. Samsonov, V. L. Ruposov, Research of economic factors of hightechnology production (Irkutsk State Technical University, Irkutsk, 2013)

11. A. D. Murzin, Scientific Review, 9, 720-723 (2013)

12. V. L. Ruposov, V. V. Khan, M. Yu. Tolstoy, Analysis of socio-economic models of public-private partnerships using the example of Energoservice (Irkutsk National Research Technical University, Irkutsk, 2015)

13. V. L. Ruposov, Proceedings of the Irkutsk State Technical University, 4(87), 213-220 (2014)

14. A. V. Bogoviz, S. V. Lobova, Y. A. Bugai, Advances in Intelligent Systems and Computing, 622, 30-36 (2018)

15. A. V. Bogoviz, S. V. Lobova, Y. V. Ragulina, A. N. Alekseev, International Journal of Energy Economics and Policy, 8(3), 67-75 (2018)

16. A. A. Askarov, E. V. Stovba, Bulletin of the Belgorod University of Cooperation, Economics and Law, 4, 178-184 (2012) 